\title{
doispontos:
}

\section{A arqueologia de Foucault entre estrutura e história}

\author{
Fernando Gimbo \\ sepefernando@gmail.com \\ Universidade Federal do Cariri (UFCA), Juazeiro do Norte, Brasil
}

\begin{abstract}
Resumo: Primeiramente, o artigo localiza a arqueologia foucaultiana dentro da tensão entre estrutura e história que acossava o pensamento francês na década de 60. A partir disso, reconstruímos a importância da análise sincrônica estruturalista e da história serial desenvolvida pela Escola dos Annales como recursos importantes para a compreensão da forma inovadora como Foucault articula estrutura e história dentro de As palavras e as coisas. O objetivo final é salientar o caráter propedêutico do livro de 66 que, ao negar uma filosofia da história ainda marcada por certa antropologia, acaba por realizar ao seu modo uma crítica da razão moderna.
\end{abstract}

Palavras-chave: Foucault; estrutura; história; crítica; razão.

\section{Foucault's archeology between structure and history}

Abstract: First, the article inscribes the foucauldian archeology within the tension between structure and history that haunted the French thought in the sixties. From this, we reconstruct the importance of structuralism and the Annales school as important resources for understanding the innovative way Foucault articulates structure and history in "The order of things". From that, it seeks to highlight the propedeutic character of the book which, by deconstructing certain philosophy of history, realizes a critique of modern reason.

Keywords: Foucault; structure; history; critique; reason.

O que quer dizer, de um modo geral: não mais poder pensar um pensamento e inaugurar um pensamento novo?

- Michel Foucault

\section{ESTRUTURA E HISTÓRIA: O PROBLEMA}

A arqueologia de Foucault pode ser compreendida como uma descrição histórica de sistemas de possibilidade do saber. A grande tese de um livro como As palavras e as coisas é que cada uma das epistemes estudadas (renascimento, classicismo e modernidade) partilham diferentes conjuntos de regras e condições que possibilitam determinados discursos com pretensão de verdade. Ao descrever tais condições e regras a arqueologia se distancia das expectativas fundacionistas de um sujeito soberano, enfatizando como o jogo do pensar se arma anteriormente a distinção clássica entre sujeito e objeto: há sempre um pensa-se (on pense) anterior ao eu penso (je pense). O que significa dizer que a arqueologia escreverá suas histórias a partir do reconhecimento de certos sistemas impessoais que determinariam o que é possível e impossível de ser pensado, dito e percebido em dado momento histórico. Como sintetiza um comentador arguto como Lebrun (1989, p. 49): 
[...] para Foucault, seria impossível pensar, durante o Renascimento, alguma coisa como o vivente; impossível à época do homem preservar a transparência do cogito; necessário que a história natural seja contemporânea de Descartes.

Contudo, tal posição traz em si uma dificuldade central. Isso porque, em As palavras e as Coisas, Foucault acaba por se colocar entre o campo da história e o campo dos sistemas de saber recusando tanto uma análise linear e causal, quanto um desenvolvimento dialético. Positivismo e dialética serão criticados no livro de 66, assinalando uma recusa às formas dominantes de filosofia da história tal como ela se estabelecera a partir da modernidade (FOUCAULT, 2007, cap. VII). A dita "morte do homem" não se diz apenas no abandono de uma filosofia da consciência, mas também em torno de uma certa suspeita de que a história seja o campo de totalização da experiência humana. Nesse caso, Foucault precisará arriscar-se no jogo entre contingência e necessidade buscando entrelaçá-las de forma inovadora em sua arqueologia, uma vez que sua crítica descarta os recursos à autoafecão fundante da consciência ou ao telos histórico da Razão.

Nesse caso, como compreender a fina tensão e articulação entre, por um lado, uma história contingente e, por outro lado, uma rigorosa formalização sistêmica do saber? Como, em última análise, relacionar aquilo que é da ordem de um tempo sem telos com uma inscrição discursiva capaz de repetir e produzir efeitos materiais no espaço? Responder tais questões, parece-me, é condição para uma compreensão mais ampla de certas premissas e consequências filosóficas de As palavras e as coisas.

Para tanto, parto de uma afirmação categórica de Foucault (2001c, p. 611):

O que tentei fazer foi introduzir análises de estilo estruturalista em domínios nos quais elas ainda não tinham ainda penetrado, ou seja, no domínio da história das ideias, da história dos conhecimentos, da história da teoria.

É assim que Foucault define seu propósito em uma entrevista de 1967, portanto, pouco depois da publicação de As palavras e as coisas. Declaração duplamente desconcertante, pois por um lado, sabemos como mais tarde Foucault irá negar veemente tal identificação com o estruturalismo e, por outro lado, é legítimo se perguntar como um pensamento marcado por uma profunda sensibilidade histórica poderia andar de mãos dadas com as análises formais tão características das investigações estruturais. Nos encontramos, em síntese, perante o problema da dicotomia entre "história e estrutura" que acossava o pensamento francês à época.

Tal problema é importante, uma vez que eu gostaria de mostrar como certos recursos a ideias comuns ao estruturalismo facilita uma compreensão mais ampla do livro de 66. Além disso, sem enfrentarmos a forma como Foucault desarma a suposta dicotomia entre história e estrutura provavelmente percamos um dos aspectos centrais de sua experiência intelectual, a saber, a reformulação de um pensamento filosófico sobre a história. Dupla tarefa, portanto: (1) mostrar como Foucault pode recusar a neutralização do tempo e da história que a dinâmica sincrônica interna da estrutura supostamente exigiria; (2) marcar a transformação conceitual que a arqueologia apresenta em torno da ideia de uma história narrativa e linear. Dessa forma, deixo de lado as polêmicas de Foucault com seus contemporâneos - assim como as tediosas discussões classificatórias: "Foucault, um estruturalista?" - e sigo inicialmente esta indicação dada por ele antes da cisma com a estrutura ${ }^{1}$.

\section{2. É O ESTRUTURALISMO AHISTÓRICO?}

Em seu interessante estudo sobre o lugar da história no pensamento de Sartre e Foucault, Thomas Flynn (2005, p. 49) dizia que “[...] a popular imagem de Foucault como estruturalista deveria ser seriamente questionada uma vez que nós consideremos a importância e a presença do 'acontecimento' em suas 
histórias". Essa perspicaz afirmação nos auxilia, uma vez que bem determina os contornos da questão: afinal, segundo uma doxa comum, o estruturalismo seria o campo das análises e descrições sincrônicas de uma língua, nada tendo em relação às dinâmicas diacrônicas de mutação.

Saussure, em seu célebre Curso de Linguística geral, estabelecia tal distinção a partir das ideias de uma "linguística estática" e uma "linguística evolutiva" (SAUSSURE, 1983, p. 94-116). A primeira seria uma ciência das simultaneidades, "[...] concernente às relações entre coisas coexistentes, de onde toda intervenção do tempo se exclui"; já a linguística evolutiva consideraria as coisas temporalmente em "suas respectivas transformações" (SAUSSURE, 1983, p. 95). Tal distinção era exigida pelo próprio objeto de estudo, a língua, devido às duas perspectivas pelas quais ela poderia ser abordada: (1) em seu aspecto de sistema em que uma série de relações entre elementos diversos construiria o valor momentâneo de seus termos; (2) em sua dinâmica histórica, isto é, na passagem entre um sistema e outro a partir da transformação de certas relações entre elementos.

A sincronia diz respeito a uma ciência do espaço, um instantâneo de um sistema em dado momento. A diacronia, por sua vez, seria um eixo temporal de desenvolvimento. Saussure (1983, p. 100) apresenta o seguinte gráfico geral como representação da relação de complementariedade entre as duas dimensões de análises (Gráfico 1).

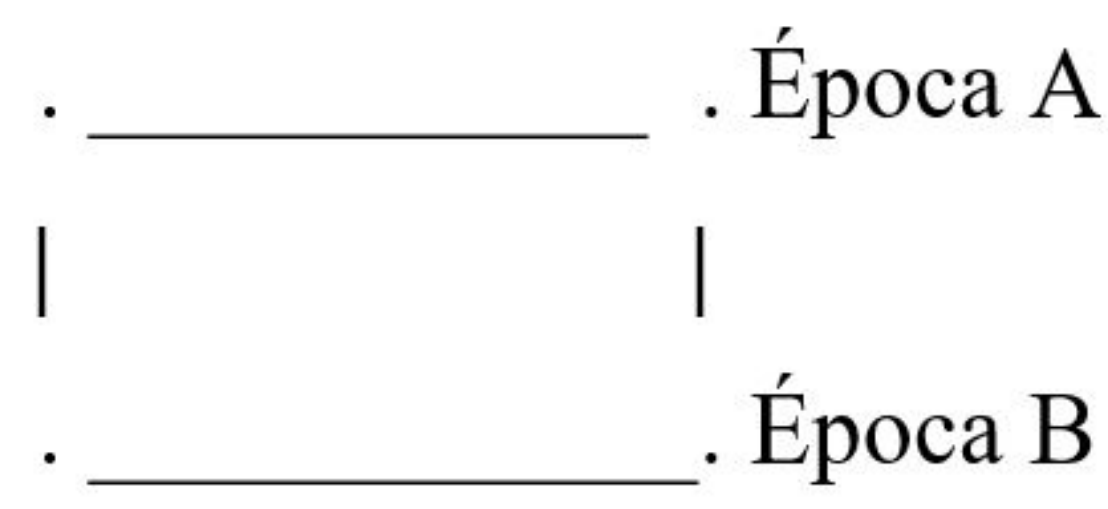

Gráfico 1. Figura apresentada por Saussure para ilustrar a relação entre sincronia e diacronia.

O eixo horizontal diz respeito à sincronia, a descrição de simultaneidades de relações de um sistema fechado a ser analisado, um modelo linguístico dado no caso de Saussure. Já os eixos verticais representam a diacronia, sequência de eventos históricos que marcam a passagem de um sistema A para B.

Por exemplo: Saussure nos lembra como em francês o acento recai sempre sobre a última sílaba, a não ser que esta tenha um $e$ mudo (âme). Trata-se de uma relação estrutural entre o conjunto das palavras francesas e o acento (corte horizontal B). Mas de onde deriva tal regra? Do latim antigo, em que "[...] o acento recaía na penúltima sílaba quando esta era longa; se fosse breve o acento recaía na antepenúltima: amícus, ánima” (corte horizontal A) (SAUSSURE, 1983, p. 101). Tal lei de relação da língua latina entre as palavras e os acentos não conhece nenhuma analogia direta com o sistema da língua francesa, mesmo que possamos estabelecer uma comparação entre os acentos: "sem dúvida é o mesmo acento, no sentido de ter permanecido nos mesmos lugares; na palavra francesa recai sempre na sílaba que o levava em latim: amícum - ami, ánima - âme” (SAUSSURE, 1983, p. 101). Trata-se do mesmo acento, porém a relação entre ele e as palavras se alterou, uma vez que a grafia destas mudou: "[...] tudo o que vinha após 
o acento ou desapareceu ou se reduziu a 'e' mudo" (eixo vertical do gráfico) (SAUSSURE, 1983, p. 101). Esta transformação de uma relação entre elementos dentro do sistema da língua, a partir de seu uso cotidiano, desencadeia efeitos contingentes em diversas direções dentro do sistema:

[...] desde então, as pessoas conscientes dessa nova relação colocaram instintivamente o acento sobre a última sílaba (antes do "e" mudo) mesmo em palavras de empréstimo transmitidas pela escrita (facile, consul, ticket, brugrave, etc). (SAUSSURE, 1983, p. 102).

Com este simples exemplo, podemos melhor definir o que estava em jogo naquilo que deu origem ao estruturalismo como modo de análise. Trata-se de mostrar que caso pensemos o objeto de estudo como um conjunto de relações, todas as partes devem ser consideradas em sua solidariedade sincrônica para que possamos compreender sua logicidade interna. Tal recorte - que ignora metodologicamente o eixo temporal - revela uma dimensão de análise em que as relações de causalidade não são o único marcador epistemológico de racionalização de um objeto a ser conhecido. A regra do acento, no caso, diz respeito à disposição de termos e suas relações dentro de um sistema linguístico, logo, ela não pode ser derivada causalmente da alteração da grafia das palavras, ainda que esta seja necessária para o deslocamento da regra:

[...] sem dúvida, cada alteração tem sua repercussão no sistema; o fato inicial, porém, afetou um ponto apenas; não há nenhuma relação interna com as consequências que se podem derivar para o conjunto. (SAUSSURE, 1983, p. 103).

Consequentemente, esta forma de análise insere um drástico nível de acaso na dinâmica das transformações: nela, uma alteração diacrônica - ainda que possa ser pensada historicamente a partir da noção de causalidade - reverbera em séries divergentes sendo impossível reconstituir tudo em termos de causa e efeito. Em outras palavras, tal modelo de análise traz como consequência uma limitação à narrativa causalista, uma vez que pensa as passagens entre estruturas a partir deste desbalanço autônomo e constitutivo². Por isso a importância dada tanto à reconstituição do sistema respeitando sua logicidade interna - o que Michel Serres chama de modelo (SERRES, 1990) - quanto ao método comparativo entre sistemas distintos (o que é sintetizado no gráfico de Saussure já referido). Podemos dizer, em suma, que um dos traços maiores e constitutivos daquilo que chamamos estruturalismo é o trabalho analítico-comparativo sobre este espaço de signos em que o historicismo não tem o privilégio de ser o único índice de racionalização do real.

É a partir de elementos retirados das análises de Saussure e importados para campos diversos das ciências humanas que toda uma nova geração de pensadores franceses, na década de 50 e 60, colocava em suspeita essa confiança que a filosofia depositara no processo histórico a partir da modernidade. Crítica de uma filosofia da história que anda de mãos dadas com uma violenta recusa ao humanismo teleológico que esta pressupõe. Como dirá Lévi-Strauss (1990, p. 312-313):

\footnotetext{
Mas existe um outro meio de eludir o dilema sem por isso destruir a história. Basta reconhecer que a história é um método ao qual não corresponde um objeto específico e, por conseguinte, recusar a equivalência entre a noção de história e a de humanidade que nos pretendem impor como o fito inconfessado de fazer da historicidade o último refúgio de um humanismo transcendental, como se, com a única condição de renunciar aos seus "eus" por demais desprovidos de consistência, os homens pudessem reencontrar no plano do nós a ilusão da liberdade. De fato, a história não está ligada ao homem nem a nenhum objeto particular. Ela consiste, inteiramente, em seu método, cuja experiência prova que ela é indispensável para inventariar a integralidade dos elementos de uma estrutura qualquer, humana ou não-humana. [...] Tal como se diz de algumas carreiras, a história leva a tudo, mas com a condição de sair dela.
}

Tal trecho expressa de forma exemplar a aventura do pensamento estruturalista e seus sucessivos encontros polêmicos com outras importantes correntes do cenário intelectual francês ${ }^{3}$. Mas marca, também, a ambiguidade da relação de Foucault com o estruturalismo. Isso porque, se é certo que Foucault subscreva a boutade levistraussiana contra o humanismo, é impossível pensá-lo como alguém que defenda 
uma "saída da história". Daí o lugar em que a questão surge e patina: pois, será que malgrado a ênfase na complementariedade entre as dimensões sincrônicas e diacrônicas, o estruturalismo - Lacan, Althusser, Barthes, Lévi-Strauss, Dumézil - ao colocar em jogo um conceito de história que a seus olhos pareceria por demais devedor de uma tradição metafísica tão característica do pensamento ocidental, não recairia no erro, ou perigo, de um ahistoricismo quase clássico? Ou, o que é ainda pior aos olhos da filosofia, de lançar-nos em uma história mallarmaica que apenas conhece os golpes do acaso?

Problema que não apenas Sartre, mas também Derrida já levantava em seu belo ensaio sobre o etnólogo francês: "Mais concretamente, no trabalho de Lévi-Strauss, é preciso reconhecer que o respeito da estruturalidade, da originalidade interna da estrutura, obriga-o a neutralizar o tempo e a história" (DERRIDA, 1967, p. 427). O mesmo Derrida que continua em um comentário que, praticamente sem alterações, poderia ser direcionado ao Foucault de As palavras e as coisas:

[...] a aparição de uma nova estrutura, de um sistema original, faz-se sempre - e é a própria condição da sua especificidade estrutural - através de uma ruptura com o seu passado, a sua origem e a sua causa. Só se pode, portanto, descrever a propriedade da organização estrutural não levando em conta, no próprio momento dessa descrição, as suas condições passadas: omitindo colocar o problema da passagem de uma estrutura para outra, colocando entre parênteses a história. Neste momento "estruturalista", são indispensáveis os conceitos de acaso e de descontinuidade. (DERRIDA, 1967, p. 428).

Distante da polêmica fácil entre dialética e estruturalismo, encontramos um pensador como Derrida - pouco comprometido com a dialética - sintetizando de forma concisa a tensão, ou contradição, entre a análise estrutural e a exigência moderna de uma aguda consciência histórica. Voltamos, portanto, ao nosso ponto de partida: entender essa tensa posição de Foucault que, ao mesmo tempo em que retoma alguns métodos da análise estrutural, não deixa de localizar seu pensamento dentro da história. Para compreendemos como Foucault pôde desarmar tal dicotomia, é preciso atentar para seu inventivo trabalho de articulação entre elementos derivados tanto do estruturalismo, quanto das práticas desenvolvidas pela Escola dos Annales: "As duas noções fundamentais da história, tal como ela se faz hoje, não são mais o tempo e o passado, mas a transformação e o acontecimento" (FOUCAULT, 2001f, p. 1141). Comecemos pelo que Foucault compreende por transformação.

\section{SINCRONIA E DESCONTINUIDADES}

Em 1969, Foucault publica um ensaio intitulado "Linguistique et sciences sociales" (FOUCAULT, 2001d, p. 849-870). Nele - originalmente uma conferência no Japão - Foucault discute uma série de problemas relacionados à linguística estrutural e às ciências humanas como forma de lançar luz sobre suas pesquisas. Tal discussão nos parece exemplar para um maior aprofundamento da já discutida presença estruturalista no interior da reflexão arqueológica e sua tensão com a história. Por esse motivo, sigamos inicialmente de perto esse ensaio de 69.

Foucault começa explicando que a linguística estrutural - "Saussure e seus sucessores" - diz respeito à análise formal e científica de um conjunto de relações entre elementos diversos, por exemplo, no caso de uma língua. Tal análise não se reduz à coleção empírica de átomos individuais (raízes, flexões gramaticais, ou mesmo palavras), pelo contrário, o que há de notável e inovador nesse método é exatamente que

[...] tais relações são independentes nelas mesmas, quer dizer, em sua forma; [...] é neste sentido que elas são generalizáveis, sem metáfora alguma, e podem eventualmente serem transportadas a algo bastante diferente dos elementos de uma natureza linguística. (FOUCAULT, 2001d, p. 851). 
O que Foucault sustenta durante todo o ensaio é que com a linguística estrutural surge um novo estilo de análise passível de ser transposto para outros campos do conhecimento, por exemplo, para a sua problemática de uma história dos sistemas de pensamento. Buscar esta relação irredutível aos elementos empíricos, buscando formalizá-la em termos sistêmicos, seria, como já vimos, a grande especificidade e inovação do método estruturalista, inovação que rapidamente disseminou-se para diversas áreas das ciências humanas.

Mas, como compreender as consequências de tal estilo de racionalização para a reflexão foucaultiana e sua exigência de ancoragem histórica? Segundo Foucault (2001d, p. 852), a mais importante consequência é, precisamente, a recusa de uma reflexão exclusivamente causal:

Tradicionalmente, a racionalização do empírico se fazia através e graças a descoberta de um certo tipo de relação, a relação de causalidade. Pensávamos que tínhamos racionalizado um domínio empírico quando podíamos estabelecer uma relação de causalidade entre um fenômeno e outro. E agora, graças à linguística, descobrimos que a racionalização de um campo empírico não consiste somente em descobrir e poder assinalar esta relação precisa de causalidade, mas a expor todo um campo de relações que são provavelmente semelhantes às relações lógicas. [...] Nos encontramos assim na presença de um instrumento formidável de racionalização do real, e nos apercebemos que esta racionalização tão fecunda do real não passa mais pela designação do determinismo e da causalidade. Eu acredito que este problema de uma lógica que não é a lógica da determinação causal está atualmente no coração dos debates filosóficos e teóricos.

Não é sem razão que Foucault privilegie tal discussão, afinal, a ausência de nexos causais já era - à época - a principal crítica às análises arqueológicas presentes em As palavras e as coisas, sobretudo por parte de Sartre e da tradição marxista. Segundo Foucault, entretanto, a análise estrutural não é absolutamente ahistórica, pois sua astúcia consiste simplesmente em não identificar o histórico unicamente com a dimensão do sucessivo.

O ponto de vista da linguística estrutural é sincrônico e escolher a sincronia não é "[...] escolher o presente contra o passado e o imóvel contra o evolutivo" (FOUCAULT, 2001d, p. 854). O sucessivo é apenas uma das dimensões da história, uma vez que "[...] a simultaneidade de dois acontecimentos não é menos um fato histórico do que sua sucessão” (FOUCAULT, 2001d, p. 854). Não identificar história e sucessão, como fazemos comumente, é admitir que a história seja tanto o simultâneo quanto o sucessivo. Para além da linha cronológica há, também, o tempo em seu caráter de simultaneidade, de séries de acontecimentos que divergem e convergem produzindo um espaço de relações. A questão é colocada, consequentemente, para além da dicotomia entre espaço e tempo, pois o importante para um pensamento do espaço heterótopico, como a arqueologia, é à exigência de uma nova imagem do tempo, muito diferente daquela construída pela filosofia moderna:

Isto quer dizer, primeiramente, que o espaço europeu não é o espaço em sua totalidade, vive-se em uma série de espaços polimorfos; em segundo lugar, a ideia é que não há uma só história, há diversas, diversos tempos, diversas durações, diversas velocidades, que se encadeiam umas com as outras, que se cruzam e formam precisamente os acontecimentos. (FOUCAULT, 2001j, p. 581).

Esse movimento é central para o desarme da dicotomia entre estrutura e história por parte de Foucault. Trata-se de afirmar que a análise sincrônica não é contraditória ao tempo em-si, mas sim a certa imagem do tempo pressuposta pela história a partir da modernidade. Tempo compreendido como uma grande forma vazia, condição de possibilidade do sentido interno da consciência e marcado pela continuidade e pela capacidade de síntese fundada na identidade de um sujeito histórico. Tal concepção do tempo é simétrica a uma imagem da história construída como unidade no devir, escoamento entre duas presenças, grande narrativa que pode ser plenamente determinada a partir do (re)encadeamento necessário entre eventos. É essa imagem da história que será rejeitada por Foucault. 
Nesse caso, recusa-se a falsa dicotomia entre ou uma análise histórica ou um pensamento sistêmico. Através do estruturalismo, mas para além dele, outro problema surge nas mãos de Foucault: qual imagem do tempo e qual forma de fazer história pode se coadunar com esta análise sincrônica do espaço de aparição de um discurso? Não mais se trata de decidir de forma polêmica entre uma coisa, ou outra. Antes, trata-se de constituir uma maneira de pensar necessidade do saber $e$ contingência histórica, formalização espacial $e$ temporalização, sistemas de pensamento $e$ séries de acontecimentos.

A lição que Foucault toma do estruturalismo - de certa forma virando-a contra o próprio estruturalismo - diz que para um objeto de estudo aparecer em sua singularidade é preciso compreender sua sistematicidade interna. Contudo, antes de descartar a história, tal movimento permite que ela apareça como um movimento de diferenciação constante e não mais como a contraprova de uma hipótese progressista. Através de uma reelaboração do estruturalismo, Foucault faz surgir em sua arqueologia um paradoxo no cerne da história: o historicismo precisa sempre lançar mão de algo ahistórico, seja a forma unitária do progresso, seja a direção irremediável de um telos. Não há historicismo sem uma dimensão - fora da história - que o funda. Com a análise sincrônica, trata-se de colocar a progressão e a reflexão teleológica em parêntese para favorecer a categoria de transformação, o que acaba por trazer para o primeiro plano o conjunto de diferenças entre os sistemas analisados. É assim que em As palavras e as coisas a transformação histórica e seus efeitos contingentes aparecem por-entre as descrições sistemáticas das epistemes.

Consequentemente, sugiro que para Foucault há uma relação necessária entre tempo e espaço, uma vez que o espaço ${ }^{4}$ não é mera forma vazia em que os corpos se encontram, mas antes, ele se constrói processualmente através do desdobramento histórico. Daí que Foucault possa definir sua arqueologia como "[...] o estudo do espaço no qual se desenvolve o pensamento, assim como as condições deste pensamento, seu modo de constituição" (FOUCAULT, 2001a, p. 581). Colocação importante, pois não podemos cindir tal "estudo do espaço" de seu desenvolvimento temporal, caso contrário cairíamos em uma descrição de estruturas puras - em última análise formas a priori - o que evidentemente estaria muito distante do pensamento de Foucault.

Nesse sentido, a arqueologia oscila entre temporalização e espaçamento. Há o devir-espaço do tempo - que se diz na descrição sincrônica de cada época analisada - assim como o devir-tempo do espaço - com a abertura do sistema de relações à temporalização histórica. Em outras palavras, com as epistemes trata-se sempre de um espaço-tempo. A arqueologia diz respeito à descrição retrospectiva dessas estruturas de época e, precisamente por isso, ela é impensável sem a conjunção entre tempo e espaço. Logo, Foucault - para além do estruturalismo - visaria não a negação da evolução e o elogio de uma imobilidade formal, mas sim, a análise das condições para que uma transformação sistêmica possa realmente se efetivar na história, inscrevendo-se no tempo, na materialidade do arquivo de uma época específica:

Eu quis, pelo jogo metódico [...] descrever enunciados, grupos inteiros de enunciados, fazendo aparecer as relações de implicação, de oposição, de exclusão que poderiam os ligar. [...] Disseram-me, por exemplo, que eu teria admitido, ou inventado, um corte absoluto entre o final do séc. XVIII e o começo do séc. XIX. Na verdade, quando observamos os discursos científicos no final do séc. XVIII, constatamos uma mudança muito rápida e, para dizer a verdade, fortemente enigmática ao olhar mais atento. Eu quis descrever precisamente esta transformação, dito de outra forma, estabelecer o conjunto de transformações necessárias e suficientes para passar da forma inicial do discurso científico - aquele do século XVIII - a sua forma final, aquele do século XIX. (FOUCAULT, 2001g, p. 616).

Disso, podemos extrair duas consequências maiores: primeiramente, tal análise, apesar de levar em consideração os elementos empíricos, não os considera de forma isolada. Ou seja, há um anti-atomismo nesta busca das relações sistemáticas entre os elementos. Em segundo lugar, ela sustenta que a relação entre elementos é coerente e transformável, ou seja, que os elementos constituem um sistema racionalizável. 
Consequentemente, mesmo que a sincronia faça recurso a categorias como acaso, ou arbitrariedade, ela de forma alguma pode ser considerada um irracionalismo. Pelo contrário, trata-se de um racionalismo ampliado em que se busca racionalizar formalmente campos atravessados por elementos arbitrários e aleatórios. Um pensamento sistêmico não é nem atomista, nem formalista, mas sim relacional e dinâmico, aberto sobre a contingência da transformação histórica.

Seguindo essa linha de leitura, não é difícil compreender porque em As palavras e as coisas não se trata de traçar as linhas causais da passagem de uma episteme a outra, mas sim de mostrar, entre outras coisas, as transformações no conceito de signo que possibilitam o surgimento de um novo espaço epistemológico em que biologia, economia e linguística poderão se constituir e se efetivar positivamente. Essa busca pelo "conjunto de transformações necessárias e suficientes" através das quais passamos de um discurso a outro, de uma época a outra, de uma forma histórica a outra, é o que permite a arqueologia afastar-se do a priori formal kantiano. Tal movimento faz surgir dentro do pensamento de Foucault o problema das múltiplas origens históricas ${ }^{5}$ do que ele chama de a priori. A priori, portanto, na história e não da história.

Tal gesto acaba - ao suspender o elemento ahistórico que funda o historicismo como narrativa - por encontrar a dimensão histórica dentro da problemática sistêmica, "historicizando a estrutura". Daí a tensão e superação do caráter dito "estrutural" das análises de Foucault em As palavras e as coisas: fazer história é descrever transformações inerentes aos sistemas estudados, descrição que exige que coloquemos entre parênteses as relações de causa e efeito da história narrativa; tal procedimento, entretanto, nos permite inteligir esse entre-dois que a marca a diferença e a descontinuidade entre um sistema e outro. É através dessa rachadura que se insinua entre as dobras de nosso saber que a história pode ser apreendida em seu caráter de diferença.

A descontinuidade constitui um limiar, aquilo que marca o dentro e fora de um pensamento, o vazio e o novo espaço discursivo; é o entre-épocas onde a contingência dos acontecimentos resplandecem e a cultura ganha seus contornos epocais. Nesse sentido, o estruturalismo - pelo menos para o Foucault da década de 60 - nunca foi um pensamento da primazia do formal sobre o histórico, mas sim, uma abertura capaz de propiciar outra forma de historicização da razão para além das categorias do sujeito, da consciência e do retorno garantido do idêntico.

\section{HISTÓRIA SERIAL E ACONTECIMENTO}

"O trabalho que, talvez, marcou mais profundamente os estudos em história na França a partir de 1960 não foi um trabalho de historiador, foi de um filósofo: Michel Foucault” (REVEL, 1986, p. 290). Esta afirmação eloquente de Jacques Revel - ex-diretor da "Annales d'histoire économique et sociale" expressa a importância e a relação do pensamento de Foucault com a dita geração dos "novos historiadores". Geração que ficou conhecida como "Escola dos Annales" e que dominou praticamente toda a produção mais rigorosa sobre história na França durante o séc. XX. Fundada em 1929 por Marc Bloch e Lucien Febvre, seus métodos de análise visavam, sobretudo, contornar o caráter narrativo e continuísta que constituíam a forma como tradicionalmente se fazia história (as grandes histórias das nações, das guerras, dos modos de produção, etc) para confrontar-se com a dispersão dos fatos, com periodizações diversas (curtas, médias e longas durações), dando uma atenção renovada aos sujeitos individuais e seus comportamentos, assim como a análise obsessiva dos arquivos de época. François Furet bem delimita tal transformação a partir da diferença entre uma "histoire-récit" e uma "histoire-problème" (FURET, 1986, p. 54-68). 
Para a geração dos Annales a história é, tradicionalmente, "a filha da narrativa” (FURET, 1986, p. 54). A forma narrativa, nesse caso, é a condição de possibilidade de uma história, sucessão que permite a inteligibilidade do sentido. Em outras palavras, a história desenvolver-se-ia tal como a forma ideal e unitária da vida de um sujeito: ela teria começo, desenvolvimento e fim. A partir desta linha cronológica seria possível decidir sobre os eventos principais e, ao mesmo tempo, a partir da recuperação do passado seria possível antecipar como será o futuro.

Por detrás de tal história há uma imagem - bastante devedora do senso comum - em que o tempo é apreendido como sucessão de presenças e o trabalho da consciência como um trabalho de (re)significação desse escoamento temporal. Daí que a história normalmente seja contada a partir das grandes guerras, dos desenvolvimentos de unificação de nações e das biografias dos grandes líderes, esta fastidiosa saga de homens de Estado. Cabe ao historiador decupar os eventos marcantes - Batalha de Waterloo, queda da Bastilha, invasão da Normandia - como forma de construir um encadeamento narrativo entre eventos dispersos:

O evento neste tipo de história consiste precisamente de momentos. [...] e um evento, considerado de forma isolada, é ininteligível. Para que ele ganhe significância, ele deve ser integrado em uma sucessão de eventos em relação aos quais ele ganha significado. [...] toda história narrativa é uma sucessão de eventos de origem ou, se preferirmos, uma história de eventos. E toda história de eventos é teleológica: apenas o "fim" da história torna possível a escolha e o entendimento dos eventos que a compõe. (FURET, 1986, p. 55).

Traduzo "événement", aqui, por evento. Isso porque ele diz respeito à crença de que exista algo positivo na história, um conjunto de fatos, de momentos, de experiências, que cabe à narrativa recuperar em sua totalidade.

A essa orientação em que "[...] o que vem primeiro explica o que sucede" (FURET, 1986, p. 8) a nova história se opõe a partir da ideia de uma historiografia serial. Serializar significa organizar aquilo que se passou a partir da articulação de séries distintas e não totalizáveis pela forma-narrativa. Isso porque a série é uma relação entre acontecimentos diversos que o historiador cria com o intuito de permitir algum nível de inteligibilidade de um determinado problema histórico.

Tal estratégia é descrita por Furet a partir de três pontos principais: (1) primeiramente, o historiador aceita a indeterminação gigantesca que qualquer apreensão mais rigorosa do tempo histórico nos revela. Por isso, ele abre mão das grandes narrativas, desse caráter quase mítico que os eventos têm, para construir uma periodização através da inscrição setorizada do problema a ser estudado. Em outras palavras, não se narra o passado, antes, descreve-se uma situação ao criar um problema histórico. O problema é o grande marcador epistemológico desse tipo de história; (2) ao fazer isso, o historiador abandona a concepção de história como metanarrativa e o evento perde seu caráter originário. Não se procura mais um evento definidor da história, pelo contrário, assistimos uma serialização de acontecimentos dispersos, alguns muito claros, outros praticamente imperceptíveis, alguns de curta duração, outros de longuíssima duração e que escapam a nossa capacidade de racionalização (cf. BRAUDEL, 1992, p. 41-78). O historiador, portanto, se esforça para reconstruir a partir de dados materiais concretos um quadro de inteligibilidade de uma problemática de época, respeitando a contingência, os cortes, as diferentes durações e complexidades inerentes a todo período histórico; (3) por fim, tal serialização dos acontecimentos e a constituição de problemas específicos a determinadas épocas revelam uma história que “[...] descreve continuidades de modo descontinuísta" (FURET, 1986, p. 49).

Tal concepção de como fazer história, assim como a noção de problematização histórica, foram amplamente apropriadas por Foucault como ele mesmo deixa claro nesta entrevista de 1969: 
Eu me oponho completamente a uma certa concepção da história que toma por modelo uma espécie de grande evolução contínua e homogênea, um tipo de grande vida mítica. Hoje em dia os historiadores sabem muito bem que a massa de documentos históricos pode ser combinada segundo séries diferentes que não conhecem a mesma direção nem o mesmo tipo de evolução. A história da civilização material (técnicas agrícolas, habitat, instrumentos domésticos, meios de transporte) não se desenvolve da mesma forma que a história das instituições políticas, ou a história dos fluxos monetários. Isto que Marc Bloch, Febvre e Braudel mostram para a história tout court, eu acredito que possa ser mostrado para a história das ideias, do conhecimento, do pensamento em geral. (FOUCAULT, 2001b, p. 815-816).

Foucault percebe que a Escola dos Annales propunha outra disciplina histórica em que a historicidade poderia aparecer em sua especificidade e não como a contraprova de exigências ainda por demais devedoras de uma filosofia da história e da consciência. Agora, a história das nações surge entrecortada por séries históricas divergentes: história do trigo, ou das minas de ouro; história das expansões e caminhos marítimos; história da seca, da irrigação, da fome e da proliferação de doenças. Frente tal complexidade é preciso se perguntar:

Que estratos é preciso isolar uns dos outros? Que tipo de série instaurar? Que critérios de periodização adotar para cada uma delas? Em que quadro de cronologia ampla, podem ser determinadas sequências distintas de acontecimento? (FOUCAULT, 2010, p. 4).

O problema da periodização - como destaca Fernando Novais (2005, p. 160-64) - se torna, doravante, o problema fundamental da prática historiográfica. Fundamental, pois a dificuldade nasce do fato de que aparentemente é possível encontrar critérios formais de setorialização, agrupamento e racionalização de determinados estratos, discursos e instituições históricas. Por outro lado, os ritmos variam, e os períodos de um setor não acompanha o de todos os outros. Se na realidade histórica há uma interligação entre as mais diversas histórias, quando setorializamos - história econômica, história cultural, história jurídica, etc - as várias periodizações não necessariamente coincidem, ficando justapostas e não articuladas. Daí que um critério de periodização amplo já não possa ser encontrado na forma linear da narrativa, mas sim em uma forma sistêmica de articulação - como a episteme - que, de forma parcial é verdade, ao menos consegue integrar determinados níveis aparentemente desencontrados (BALIBAR, 2015). Dessa forma, a persistência de determinada configuração estrutural muda de natureza quando se articula com novas configurações.

Disso se segue o privilégio da série por parte de Foucault. Serializar significa analisar a história de um objeto " $x$ " aceitando sua simultaneidade sincrônica $e$ a divergência de seu tempo com outras temporalidades que a encontram e a cruzam. O que significa dizer que um mesmo período histórico pode ser atravessado por diversas séries, como Braudel bem mostrara em seu clássico estudo sobre a história do mediterrâneo: "Braudel fez trabalhos muito interessantes sobre estas diferentes durações [...] um tempo breve e longo; o problema é fazer a análise desses jogos no interior do tempo" (FOUCAULT, 2001j, p. 580). Com a serialização da história nos afastamos do ritmo linear e das expectativas de totalização, pois se trata agora de precisar não a sucessão, mas as relações de vizinhança de cada elemento, sua simultaneidade, traçando o contorno de seus limites e relações ${ }^{6}:$ "[...] descrever as relações entre as diferentes séries, para constituir, assim, séries de séries" (FOUCAULT, 2010, p. 9). Tal sobreposição articulada de tempos diversos, como Foucault rapidamente percebe, pode ser relacionada diretamente com a análise estrutural e sua ênfase nas transformações inerentes a um sistema, comentário bastante importante para compreensão da recusa foucaultiana a qualquer contradição entre estrutura e história:

[...] é uma coisa importante que o estruturalismo - isso que chamamos estruturalismo - tenha feito aparecer um tipo diferente de tempo; dito de outra forma, não há apenas um tempo a maneira hegeliana ou bergsoniana, uma espécie de grande fluxo que arrastaria tudo, há histórias diferentes que se sobrepõem e se articulam. (FOUCAULT, 2001j, p. 580). 
Dessa forma, tal prática de fazer história dissocia-se de uma expectativa filosófica que visa estabelecer como através da história podemos encontrar o caminho de continuidades que determinam um horizonte totalizante para tantos espíritos de época diferentes. Como dirá de forma clara Foucault: "O problema não é mais o da tradição e do rastro, mas o recorte e o limite; não é mais o fundamento que se perpetua, e sim as transformações que valem como fundação e renovação dos fundamentos" (FOUCAULT, 2010, p. 6). O que significa dizer que é preciso desligar a história de uma imagem antropológica em que aquela apareceria como uma "[...] memória milenar e coletiva que se serve de documentos materiais para reencontrar o frescor de suas lembranças" (FOUCAULT, 2010, p. 8). Pois a dimensão histórica, ao menos para Foucault, apenas pode ser restituída retrospectivamente através de um trabalho meticuloso sobre a materialidade do documento - $\mathrm{o}$ arquivo de uma época - que visa dotar de alguma consistência e inteligibilidade períodos históricos marcados por uma heterogeneidade irredutível:

O documento não é o feliz instrumento de uma história que seria em-si mesma, e de pleno direito, memória; a história é, para uma sociedade, uma certa maneira de dar status e elaboração à massa documental de que ela não se separa. (FOUCAULT, 2010, p. 8).

A cultura limita e transforma seus contornos no perpétuo trabalho de fazer e refazer a história, pois há um entrelaçamento necessário entre história e cultura. Contudo, nenhuma síntese, ou garantia, está de antemão assegurada no campo material da história.

Dito isso, é possível sublinhar o duplo movimento instituído por Foucault entre história e filosofia: a história como prática externa à filosofia é capaz de tanto barrar a continuidade absoluta pressuposta em uma história filosofante, quanto renovar o problema filosófico da história 7 . É precisamente através da descontinuidade que a filosofia da história pode ser agora interrogada. O descontínuo como limiar, como zona de transformação de um problema, constitui para Foucualt um lugar privilegiado de apreensão da história:

Paradoxal noção de descontinuidade: é, ao mesmo tempo, instrumento e objeto de pesquisa [...] de onde poderia ele (o historiador) falar, na verdade, senão a partir dessa ruptura que lhe oferece como objeto a história - e sua própria história? (FOUCAULT, 2010, p. 11).

Em outras palavras, a descontinuidade deixa de ser um obstáculo para tornar-se uma manière de faire - lição que Foucault encontrara também na forma de história praticada pela epistemologia francesa (Koyré, Bachelard e Canchuilhem) (FOUCAULT, 2001i, p. 435). A descontinuidade não surge mais como um ponto cego que é preciso reduzir, ou contornar. Pelo contrário, ela torna-se um conceito operatório que é plenamente utilizado dentro das investigações de objetos que têm uma história. Disso segue uma inversão: o descontínuo deixa de ser uma figura negativa da ausência de nexos causais, ou de mediações dialéticas - em última instância signo da falência de um princípio de razão suficiente - para tornar-se um elemento positivo que possibilita a inteligibilidade de determinado problema a partir de suas transformações históricas. Tal imagem da história produz uma análise da continuidade des-contínua, um "espaço de dispersão" como dirá Foucault.

Nesse sentido, cabe lembrar como o prefixo latino "des" não marca apenas uma negação, mas antes uma cisão, um des-locamento intrínseco ao contínuo. Não se trata de uma fragmentação absoluta, mas simplesmente do fato de que a história não será mais compreendida como um fio transcendental dotado de um miraculoso magnetismo centrípeto capaz de cingir todos os eventos em torno de um centro único. O tempo deixa de conhecer apenas uma única duração para se constituir através de durações diversas. Tal movimento irá exigir a apreensão da des-continuidade como signo da contingência e diferencialidade próprias à força da história. 
O que sugere que não devemos rebater sobre a arqueologia foucaultianas determinadas exigências normativas que não dizem respeito ao seu pensamento, com o risco de perdermos o rigor de suas análises. Essa confusão é muito comum aos críticos de Foucault, pois, ao confundirmos o interstício entre duas epistemes com uma descontinuidade não explicada, rebate-se sobre a arqueologia um conceito de evento e uma exigência narrativa que é completamente estranha a sua obra. Nesse caso, as histórias foucaultianas apenas podem surgir como expressões de uma "história sem razão".

Todavia, o certo é que quando lemos atenciosamente os estudos de Foucault na década de 60, percebemos que nunca se trata de uma descontinuidade absoluta, mas sim, de séries de acontecimentos passíveis de articulação. Como Foucault já notara, não se trata de que o "événement" tenha desaparecido - com os novos historiadores - da maneira de fazer história. Antes, seu conceito fora reformulado: saímos da história-narrativa em que os eventos são disponibilizados sucessivamente, para uma história dos problemas em que os acontecimentos são serializados. A "estrutura contra acontecimento" era um falso dilema (NORA; LE GOFF, 2011, p. 15). Como sintetiza Flynn (2005, p. 115), o acontecimento é um

[...] conceito funcional que serve para introduzir relações diferenciais e as ocorrências do acaso no coração próprio da historiografia. A dicotomia estrutura/evento (event) é simplesmente substituída pela relação séries/acontecimentos (event).

Em última análise, o acontecimento - nas obras da década de $60^{8}$ - diz respeito à transformação e dispersão temporais pressupondo uma multiplicidade própria à história. Levar em conta essa multiplicidade no próprio fazer histórico cinde a continuidade suposta pela narrativa, abrindo-nos interstícios através dos quais podemos melhor interrogar e descrever tanto o passado, quanto compreender a contingência do presente. Como esclarece Foucault (2001j, p. 581): “[...] um acontecimento não é um segmento do tempo, é, no fundo, o ponto de intersecção entre duas durações, duas velocidades, duas evoluções, duas linhas da história".

\section{PROLEGÔMENOS PARA UMA OUTRA FILOSOFIA DA HISTÓRIA?}

Mas, se é assim, podemos voltar agora à afirmação da qual tínhamos partido: "As duas noções fundamentais da história, tal como ela se faz hoje, não são mais o tempo e o passado, mas a transformação e o acontecimento" (FOUCAULT, 2001f, p. 1141). Espero ter mostrado como ao privilegiar tanto o campo da transformação à sucessão, quanto as articulações seriais ao passado-evento, Foucault articula de forma original reflexão sistêmica e descrição histórica événementiel, dissolvendo a suposta dicotomia entre estrutura e história. Daí a recusa foucaultiana de um a priori formal uma vez que a reflexão sobre "o espaço no qual se desenvolve o conhecimento" insiste precisamente como este nunca se autonomiza plenamente da dimensão temporal da história. O oximoro filosófico - "a priori histórico" - torna-se possível. Para Foucault (2010, p. 14), enfim, a dicotomia entre estrutura e história é um falso problema ainda muito arraigado a certa imagem clássica de razão:

\footnotetext{
[...] que se fale de uma estruturalização da história, ou ao menos, de uma tentativa para superar "um conflito" ou uma "oposição" entre estrutura e devir: já há bastante tempo que os historiadores identificam, descrevem e analisam estruturas, sem jamais se terem perguntado se não deixavam escapar a viva, frágil e fremente "história". A oposição estrutura-devir não é pertinente nem para a definição do campo histórico nem, sem dúvida, para a definição de um método estrutural.
}

Talvez, possamos mesmo dizer que tal articulação entre estrutura e história, ao dissolver certos pressupostos teleológicos e antropológicos, nos abriria um novo espaço para repensarmos novamente uma filosofia da história. Salientar tal caráter propedêutico pode funcionar como uma chave de leitura para a compreensão 
de certos efeitos dentro do discurso filosófico de um livro como As palavras e as coisas. Entre nós, talvez tenha sido Bento Prado Júnior quem melhor sublinhou esse viés crítico do livro de 66:

[...] a arqueologia (Les mots et les choses) de Foucault tem uma natureza, por assim dizer, propedêutica. Corresponde a uma espécie de "Prolegômenos a todo pensamento futuro que não queira guardar o estilo onto-teo-antropológico. (PRADO JUNIOR, 2004, p. 149).

De certa forma, tal polêmica em torno da história não é nova. Como Nietzsche já insistia, o filósofo pode fazer história, mas nunca recusa o ideal. E como todo bom idealista, sua necessidade de crença apenas poderá insurgir-se contra toda investigação que retire o lugar de repouso, de certeza e reconciliação do pensamento com a práxis. Ora, não era a filosofia da história que, desde o séc. XIX, nos devolvia a esse sono tranquilizador, pergunta As palavras e as coisas? Nesse sentido, parece-me que uma das intenções maiores do livro de Foucault era mostrar como "a Razão" já não se realiza na história, pelo contrário, ela se fragmenta e transforma-se sob os golpes mudos da história: "[...] somos diferença, nossa razão é a diferença dos discursos, nossa história a diferença dos tempos, nosso eu a diferença das máscaras” (FOUCAULT, 2010, p. 160).

Sublinhe-se: delimitar as formas da racionalidade sobre o fundo da contingência histórica não deixa de ser a reformulação da velha questão moderna de uma crítica da razão. Crítica agora aguçada e apurada, pois capaz de recusar o primado do mesmo a partir de uma abertura à diferença. Disso não resulta, é certo, uma definição positiva de "Razão". Contudo, nesse declínio histórico da ideia universal de razão, surge uma visão mais clara, porque perspícua e material, da natureza variável e contingente de seus limites.

Dos nossos limites 9

\section{NOTAS}

${ }^{1}$ Isso porque sabemos como Foucault irá, sobretudo a partir do começo da década de 70 , negar qualquer relação com as análises estruturalistas. Logo, seria possível e legítimo fazer uma leitura retrospectiva em que a relação com o estruturalismo é descrita em chave crítica segundo certas exigências postas pela genealogia. O que proponho, porém, é uma leitura genética em que tento acompanhar a importância do debate em torno da dicotomia entre estruturalismo e história apenas no que diz respeito ao período dito arqueológico, sobretudo no que diz respeito As Palavras e as Coisas.

${ }^{2}$ Essa era a consequência maior a ser extraída do algoritmo $\mathrm{S} / \mathrm{s}$ (significante sobre significado) que estava na base da linguística de Saussure. Isso porque com a partilha de tal relação, a linguística nos lembrava que um significante sempre se refere a outro significante, ou seja, ele sempre se encontra dentro de uma articulação sistemática característica de uma língua e não em uma nominação direta entre palavra e o objeto. Isso significa que os elementos mínimos constitutivos de uma estrutura, suas unidades, encontram-se sempre submetidas "[...] à dupla condição de se reduzirem a elementos diferenciais últimos e de os comporem segundo as leis de uma ordem fechada” (LACAN, 2012, p. 504). Esses elementos últimos são os fonemas (em Lévi-Strauss os mitemas; no estudo de Barthes sobre a moda os “vestemas"), onde não devemos buscar uma constância fonética, mas “[...] sim o sistema sincrônico dos paraeamentos diferenciais necessários ao discernimento dos vocábulos numa dada língua” (LACAN, 2012, p. 504). O pensamento estrutural definia assim uma metodologia que recusava tanto um atomismo que consistiria em ignorar as relações constitutivas entre os elementos mínimos de uma estrutura, quanto um pensamento da totalidade em que haveria uma unidade fundante, ou uma causa necessária absoluta e imanente à organização do sistema. Isso porque a análise estrutural de uma língua - um sistema complexo de relações, porém finito - exclui qualquer totalização, ou apreensão atomista. Daí a importância do conceito de jogo, isto é, de substituições e movimentos infinitos dentro de um conjunto finito de elementos (como no xadrez, por exemplo). Este sistema finito, diferente do pensamento clássico, propicia uma infinidade de substituições porque a ausência de um centro último lhe é constitutiva: "[...] centro que detenha e fundamente o jogo das substituições" (DERRIDA, 1967, p. 423). 
${ }^{3}$ A respeito desta querela, Foucault (2001j, p. 579) diz: "O caso de Lévi-Strauss permanece exemplar: foi absolutamente necessário a ele liberar seu campo de investigação e seu método da dominação do tempo hegeliano, teoteleológico, para garantir a autonomia de sua pesquisa em antropologia estrutural. Este ato de liberação foi apenas possível com o postulado das pluralidades de espaços e suas diferenças em relação ao espaço ocidental”.

${ }^{4}$ A noção de espaço é definida e retrabalhada por Foucault em As palavras e as coisas de forma próxima ao estruturalismo. A esse respeito, cabe lembrar como Lévi-Strauss explica de forma rigorosa que os elementos de uma estrutura "não têm significação intrínseca e nem mesmo designação extrínseca. Eles têm apenas um sentido que é definido de forma relacional a partir única e necessariamente de sua posição dentro da estrutura” (LÉVI-STRAUSS, 1958). É por isso que o espaço visado pela análise sincrônica não é uma extensão real, mas sim de um topos estrutural. Como sintetiza Deleuze: "Aquilo que é estrutural é o espaço, mas um espaço inextenso, pré-extensivo, puro spatium constituído cada vez mais como ordem de vizinhança, em que a noção de vizinhança tem precisamente, antes, um sentido ordinal e não uma significação de extensão" (DELEUZE, 2002, p. 225). Espaço, portanto, constituído e entrecortado por relações entre seus elementos. Daí que o que importe a Foucault em seu livro de 66 não seja as palavras em si, ou as coisas nelas mesmas, mas sim suas vizinhanças, o espaço pela qual elas se refletem e se entrecruzam, suas relações definidas em termos sistemáticos. Espaço que, certa vez, ele chamará de heterotópico: "É o espaço do fora [...] espaço no qual nós vivemos, pelo qual somos lançados fora de nósmesmos, no qual se desenrola precisamente a erosão de nossa vida, de nosso tempo e de nossa história, este espaço que nos atormenta e nos marca é em si-mesmo também um espaço heterogêneo. Dito de outra forma, não vivemos dentro de uma espécie de vazio, ao interior do qual poderíamos situar os indivíduos e as coisas. Não vivemos no interior de um vazio que se colore de diferentes reflexos, vivemos no interior de um conjunto de relações que definem posições irredutíveis umas às outras" (FOUCAULT, 2001h, p. 1575).

${ }^{5}$ Como se sabe, o problema da emergência histórica é colocado em primeiro plano quando Foucault distinguir, na esteira do pensamento nietzschiano, entre Ursprung e Entstehung (FOUCAULT, 2001e, p. 1004-1024). É certo que a entrada da problemática do poder e da causa genética de certas transformações históricas irão alterar a forma como Foucault realiza suas investigações e toda uma crítica ao modelo estruturalista será desenvolvido a partir de então. Contudo é importante notar como, ao mesmo tempo, a genealogia se apoia nos resultados arqueológicos de historicização do transcendental e recusa de uma teleologia progressista. Resultados esses obtidos a partir de uma análise focada na historicidade de sistemas de saber e não de relações de poder e dominação. Daí a importância de compreendermos tanto as linhas de descontinuidade, quanto de continuidade, no que toca a passagem entre as pesquisas da década de 60 e 70.

${ }^{6}$ De certa forma, em As palavras e as coisas, encontramos por parte de Foucault uma tentativa de articulação ampla com os livros anteriormente publicados. Isso porque as epistemes claramente "se repetem" tanto em $A$ história da loucura, quanto em $O$ nascimento da clínica, o que sugere uma forma de articulação entre problematizações diferentes - loucura, patologia/morte e ciências humanas - a partir do livro de 66.

${ }^{7}$ Sublinhe-se que não se trata de confundir filosofia e história, mas sim de abrir a filosofia ao contato da historicidade dos problemas que se diz na história das coisas, das práticas e dos discursos. Problematizações essas que dizem respeito à história do pensamento e da filosofia em geral: relação entre razão e não-razão; relação de adequação entre as palavras e as coisas, entre signo e referente; relação entre verdade e sujeito; etc. O que coloca o discurso de Foucault em uma área completamente diferente da historiografia. Nesse sentido, meu objetivo não é propor uma identificação de Foucault com a nova história, identificação, diga-se de passagem, impossível perante a heterogeneidade que constitui também essa escola; mas sim assinalar como Foucault pode fazer a historiografia entrar em contato com a reflexão filosófica, abrindo questionamentos que apontam para uma crítica de formas dominantes de conceber a história por parte da filosofia.

${ }^{8}$ Quando Foucault alterar a sua investigação centrando-a no problema das relações de poder, ele irá criticar a incapacidade do estruturalismo em dar conta do acontecimento, sobretudo enquanto acontecimento político, enquanto acontecimentos relacionados a uma lógica de governo. "Daí a recusa das análises que se referem ao campo simbólico ou ao campo das estruturas significantes, e o recurso às análises que se fazem em termos de genealogias das relações 
de força, de desenvolvimento estratégico, de táticas [...] A história não tem "sentido", o que não quer dizer que seja absurda ou incoerente. Ao contrário, é inteligível e deve poder ser analisada em seus menores detalhes, mas segundo a inteligibilidade das lutas, das estratégias, das táticas. Nem a dialética (como lógica de contradição), nem a semiótica (como estrutura da comunicação) não poderiam dar conta do que é a inteligibilidade intrínseca dos confrontos. A "dialética" é uma maneira de evitar a realidade aleatória e aberta desta inteligibilidade reduzindo-a ao esqueleto hegeliano; e a "semiologia" e uma maneira de evitar seu caráter violento, sangrento e mortal, reduzindo-a à forma apaziguada e platônica da linguagem e do diálogo" (FOUCAULT, 1979, p. 5). Doravante, segue-se tanto uma reestruturação de certos conceitos centrais à experiência intelectual foucaultiana, quanto uma ressignificação crítica de sua relação com o estruturalismo. Note-se, por fim, que o estruturalismo visado na entrevista de Foucault é, sobretudo, o de Lévi-Strauss e o de R. Barthes e não especificamente sua apropriação singular do caráter sistêmico das análises estruturais, ainda que ele também marque um certo déficit de suas análises anteriores no que tange o caráter político.

${ }^{9}$ Devo marcar minha dívida nessas formulações com o diálogo entre Bento Prado Júnior e Arley Moreno, em Erro, ilusão e loucura (PRADO JUNIOR, 2004, p. 23-76).

\section{REFERÊNCIAS}

BALIBAR, E. 2015. Quasi-transcedentals: Foucault's point of heresy and the transdisciplinar function of episteme. Theory, Culture \& Society, v. 32, n. 5, p. 45-77.

BRAUDEL, F. 1992. Escritos sobre a história. São Paulo: Perspectiva.

DELEUZE, G. 2002. Em que podemos reconhecer o estruturalismo. In: A ilha deserta. São Paulo: Illuminuras.

DERRIDA, J. 1967. L'écriture et la différence. Paris: Seuil.

FLYNN, T. 2005. A poststructuralist mapping of history. Chicago: The Chicago University Press.

FOUCAULT, M. 1979. Verdade e poder. In: Microfísica do poder. Rio de Janeiro: Graal. . 2001a. Dits et écrits. Paris: Gallimard. v. 1.

.2001b. La naissance d'um monde. In: Dits et écrits. Paris: Gallimard. p. 814-817.v. 1.</unknown>

. 2001c. La philosophie structuraliste permet de diagnostiquer ce qu'est “aujourd'hui”. In: Dits et écrits. Paris: Gallimard. p. 608-612.

.2001d. Linguistique et sciences sociales. In: Dits et écrits. Paris: Gallimard. p. 849-870. v. 1.

. 2001e. Nietzsche, la généalogie, l’histoire. In: Dits et écrits. Paris: Gallimard. p. 1004-1024. v. 1.

.2001f. Revenir à l'histoire. In: Dits et écrits. Paris: Gallimard. p. 1136-1141. v. 1.

.2001g. Sur les façons d'écrire l'histoire. In: Dits et écrits. Paris: Gallimard. p. 613-627.v. 1.

.2001h. Des espaces autres. In: Dits et écrits. Paris: Gallimard. p. 1571-1581. v. 2.

.2001i. Dits et écrits. Paris: Gallimard. v. 2.

.2001j. La scène de la philosophie. In: Dits et écrits. Paris: Gallimard. p. 571-594. v. 2. 
.2007. As palavras e as coisas. São Paulo: Martins Fontes.

2010. Arqueologia do saber. Rio de Janeiro: Forense Universitária.

FURET, F. 1986. De l'histoire-récit à histoire-problème. In: L'atelier de l'histoire. Paris: Flammarion.

LACAN, J. 2012. Escritos. Rio de Janeiro: Zahar.

LEBRUN, G. 1989. Notes sur la phénoménologie dans Le mots et le choses. In: Michel Foucault philosophe. Paris: Editions du Seil.

LÉVI-STRAUSS, C. 1958. Anthropologie structurale. Paris: Plon. v. 1 e v. 2. 1990. La pensée sauvage. Pocket.

NORA, P.; LE GOFF, J. 2011. Faire de l'histoire. Folio.

NOVAIS, F. 2005. Aproximações: estudos de história e historiografia. São Paulo: Cosac Naif.

PRADO JUNIOR, B. 2004. Erro, ilusão e loucura. São Paulo: 34.

REVEL, J. 1986. Foucault, Michel, 1926-84. In: BURGUIÈRE, A. (Ed.). Dictionnaire des Sciences Historiques. Paris: Presses Universitaires de France.

SAUSSURE, F. 1983. Curso de linguística geral. 10. ed. São Paulo: Culrix.

SERRES, M. 1990. Diálogo sobre a ciência, a cultura e o tempo: conversas com Bruno Latour. Lisboa: Instituto Piaget. 